Check for updates

Cite this: RSC Adv., 2018, 8, 33000

Received 7th July 2018

Accepted 18th September 2018

DOI: 10.1039/c8ra05793a

rsc.li/rsc-advances

\section{Synthesis and characterization of a novel antibacterial material containing poly(sulfobetaine) using reverse atom transfer radical polymerization $\uparrow$}

\author{
Xiaohong Chu, t $^{\mathrm{ab}}$ Ming Zhang, t $^{\mathrm{ab}}$ Ninglin Zhou, iD *abc Fan Wu, ${ }^{\mathrm{ab}}$ Baohong Sun ${ }^{\mathrm{ab}}$ \\ and Jian Shen*ab
}

A novel antibacterial agent was synthesized using 2-(dimethylamino)ethyl methacrylate (DM) and sodium 3chloro-2-hydroxypropane sulfonate (CHPS). It was characterized by Fourier transform infrared spectroscopy (FTIR), NMR Spectroscopy $\left({ }^{1} \mathrm{H}\right.$ NMR), and X-ray photoelectron spectroscopy (XPS). This new agent DMCHPS was then grafted onto a polyurethane (PU) substrate via surface-initiated reverse atom transfer radical polymerization (SI-RATRP). The modified PU was characterized by FTIR and XPS. The hydrophilic properties of the PU surface before and after the incorporation of DMCHPS were determined by static contact angle (SCA) measurements. The results showed that the hydrophilicity of the PU surface after the modification was remarkably improved. MIC tests and bacterial adhesion confirmed that modified PU has good antibacterial properties. Protein adsorption experiments show that the material has a certain ability to resist pollution. Furthermore, the high survival rate of HEK293 human embryonic kidney cells shows that the modified PU has a potential use as a medicinal material.

\section{Introduction}

Polyurethane (PU) has gained acceptance in the biomedical field for its excellent mechanical properties and biocompatibility. ${ }^{1-5}$ Their segmented block copolymer character endows PUs with a wide range of versatility in terms of tailoring their related properties to satisfy specific medical requirements. PU materials have been widely used in artificial hearts, pacemaker lead insulation, implantable cardiac valves and so forth., ${ }^{6,7}$ However, with rising needs in more demanding applications, modifying their surface properties becomes essential.

A great deal of attention has been attached to controlled/ radical polymerization recently because of its great flexibility in designing well-defined polymers with narrow polydispersity, controllable molecular weight (MW), complex architecture, and multifunctional properties. ${ }^{\mathbf{8}-10}$ Among all these controlled radical processes, atom transfer radical polymerization (ATRP) is one of the most efficient and successful techniques. ${ }^{\mathbf{1 1 - 1 6}}$ Atom

ajiangsu Collaborative Innovation Center for Biological Functional Materials, College of Chemistry and Materials Science, Nanjing Normal University, Nanjing 210023, China. E-mail: zhouninglin@njnu.edu.cn; Fax: +86 25 83599188; Tel: +86 25 85891536

bjiangsu Key Laboratory of Biofunctional Materials, Jiangsu Engineering Research Center for Biomedical Function Materials, Nanjing 210023, China

${ }^{c}$ Nanjing Zhou Ninglin Advanced Materials Technology Company Limited, Nanjing 211505, China

$\dagger$ Electronic supplementary information (ESI) available. See DOI: 10.1039/c8ra05793a

\$ These authors contribute equality to this work. transfer radical polymerization (ATRP) is based on a fast, dynamic equilibrium established between the dormant species (alkyl halides) and active species (radicals), with transition metal complexes acting as reversible halogen atom transfer reagents, and therefore, resulting in negligible radical termination and controlled polymerization. ${ }^{17,18}$ Reverse ATRP differs from ATRP in the initiation step since a transition metal complex with higher valence state is adopted to activate the dormant polymer chain via an atom transfer event. Mao et al. have reported a novel kind of core shell magnetic molecularly imprinted polymer (MIP) for sulfamethazine (SMZ) was synthesized by the surface-initiated atom transfer radical polymerization (ATRP) strategy. ${ }^{19}$ Ronen et al. studied that antibacterial spacer was produced by grafting polymeric quaternary ammonium by ATRP, which displayed a localized antibacterial activity by direct contact. ${ }^{20}$ By this way, RATRP makes up two major drawbacks of ATRP, that is, the toxicity of the halide species RX and the oxidation of the catalyst $\mathrm{M}_{\mathrm{t}}{ }^{n} / \mathrm{LX}$ by oxygen in the air.

However, rare reports about antimicrobial polymers synthesized via RATRP were published in recent years. For example, Haloi et al. reported a comparative study of poly(2ethylhexyl acrylate) (PEHA) prepared via RATRP. ${ }^{21}$ Wang et al. have reported robust antimicrobial compounds and polymers derived from natural resin acids was prepared via a click reaction. ${ }^{22}$ Zheng et al. studied well-defined renewable polymers derived from gum rosin via RATRP method and thermal qualities, hydrophobicity, surface composites were studied. ${ }^{23}$ 
Additionally, zwitterionic materials have garnered interest for their extremely low fouling properties and versatility ${ }^{24}$ Their ability to resist nonspecific protein adsorption, bacterial adhesion, and biofilm formation makes them of interest for applications such as wound dressings, biosensors, contact lenses, and prosthetic coatings. ${ }^{25,26}$ Zhang et al. demonstrated that zwitterionic polymers highly resist nonspecific protein adsorption and cell adhesion and modify glass slides or other oxide surfaces to achieve super low fouling via ATRP. ${ }^{27}$ Novel cationic fragments were synthesized by Sarah A. Weicker et al. were tested to show donor ability in the coordination of specific materials. ${ }^{28}$ The structure of sulfobetaine is similar to that of 2aminoethanesulfonic acid or taurine, which is present in fairly high concentrations in animals and plants. In addition, sulfobetaine is easier to synthesize and purify. ${ }^{29-31}$ The zwitterionic and biomimetic quality of sulfobetaine-based materials and the ease in the preparation make them very attractive for biomedical applications, especially when long-term stability and high effectiveness to resist biofouling are concerned. ${ }^{32-34}$ The antibacterial agent containing the structure of the ammonium ion (betaine) is a kind of antibacterial agent which is studied in the present study, and its structure is similar to that of a large amount of taurine in nature. Because of its bionic, stability and commercial property, sulfoammonium zwitterionic material has good prospects in the biomedical field and in other areas. ${ }^{35-37}$ Research shows that the small molecule antibacterial agent having a sterilization speed, antibacterial efficacy, good color stability and good features, but there are also some shortcomings, such as poor chemical stability, drug resistance after use, and the toxic and so on. The antimicrobial group is bonded to the polymer backbone, and the polymer antibacterial material is prepared, which can improve the antibacterial property. Sulfoammonium amphoteric ion-based polymer antimicrobial agents have been widely used in water treatment, health care, food and packaging materials. ${ }^{38-40}$

In this study, we proposed a method which was not same as the existing ways to synthesize a variety of active groups of ammonium chloride (DMCHPS) with antibacterial properties. ${ }^{35,41}$ And a new type of complex catalytic system $\mathrm{CuCl}_{2} / \mathrm{CPTM}$ was designed to participate in the RATRP reaction, and the preparation of new polyurethane antibacterial coating PU-Si-g$\mathrm{P}$ (DMCHPS) was prepared. The preparation process of
DMCHPS-modified PU films was described in Scheme 1. Using FTIR, XPS, static water connected tentacles, inhibition kinetics, bacteria adhesion test, scanning electron microscope (SEM), protein adsorption, MTT cytotoxicity experimental and so on the materials were characterized, in order to get a new polymer antimicrobial coating, to effectively inhibit the adhesion and growth of bacteria.

\section{Experimental}

\subsection{Materials}

Polyurethane was purchased from Nanjing Xian-Bang Corporation $N, N$-dimethylformamide (DMF, analytical reagent) was obtained from Sinopharm Chemical Reagent Co. Ltd. 3-Chloro2-hydroxy propane sulfonate (CHPS, analytical reagent) was purchased from Aladdin Chemistry Co. Ltd. 3-Chloropropyltrimethoxysilane (CPTM, analytical reagent) was purchased from Nanjing Shuguang Corporation. Butylhydroperoxid (analytical reagent), 2-(dimethylamino)ethyl methacrylate (DM, analytical reagent) and cupric chloride (analytical reagent) were obtained from J\&K chemical Co. Ltd. All the other reagents were analytical reagent and used as received.

Human embryonic kidney cells (HEK293), provided by the Drum Tower Hospital of Jiangsu Province; Staphylococcus aureus and Escherichia coli, provided by the Jiangsu Provincial Center for Disease Control and prevention. Dulbecco's modified eagle medium (DMEM) were purchased from Thermo Fisher HyClone (USA). Fetal bovine serum (FBS) was obtained from SunShine Biotechnology Co. Ltd. (China). 3-(4,5-Dimethylthiazol-2-yl) 2,5diphenyl tetrazolium bromide (MTT) was purchased from Amresco (USA).

\subsection{Preparation of DMCHPS}

2-(Dimethylamino)ethylmethacrylate (DM) $(0.10 \mathrm{~mol})$, sodium 3-chloro-2-hydroxy propane sulfonate (CHPS) $(0.15 \mathrm{~mol})$ and polymerization inhibitor 1,4-benzenediol (hydroquinone) ( 0.10 g) were added into a $100 \mathrm{~mL}$ flask equipped with magnetic stirring. The mixture was heated to $55^{\circ} \mathrm{C}$ with the oil bath and refluxed for $20 \mathrm{~h}^{42}$ After the reaction, the crude solid mixture was collected by filtration and then washed by ethanol and acetone, respectively.

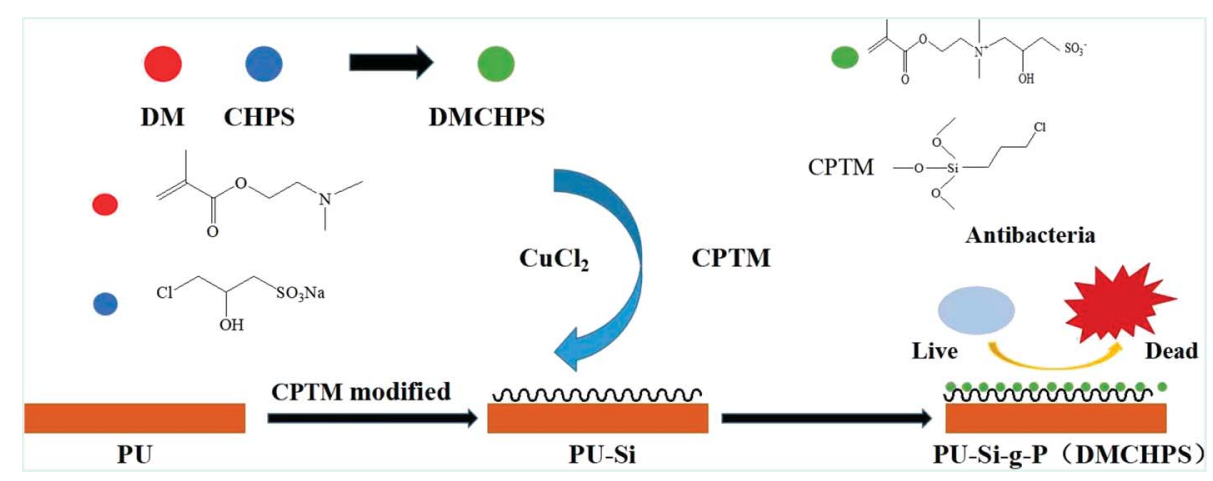

Scheme 1 A schematic illustration for the DMCHPS graft on the PU surface and the antifouling properties of modified surface. 


\subsection{Preparation and characterization of sulfobetaine modified PU}

The polyurethane (PU) particles were dissolved in the DMF solvent, and the solvent (DMF) was evaporated into the film to get the PU blank film. The film was cut into a blank PU $2 \times 2 \mathrm{~cm}$ square diaphragm, the diaphragm vertically into a concentration of $0.1 \%(\mathrm{MeO}){ }_{3} \mathrm{Si}\left(\mathrm{CH}_{2}\right)_{3} \mathrm{Cl}(0.02 \mathrm{~mL}$ silane coupling agent $+19 \mathrm{~mL}$ of water) aqueous solution, magnetic stirring for $4 \mathrm{~h}$, $48 \mathrm{~h}$ drum wind drying under $110{ }^{\circ} \mathrm{C}$, to give silylated $\mathrm{PU}$ coating. ${ }^{43}$ In order to graft DMCHPS on the PU-Si membrane surface, the reaction was carried out for a predetermined period of time using a [DMCHPS]:[TBHP]: $\left[\mathrm{CuCl}_{2} \cdot 2 \mathrm{H}_{2} \mathrm{O}\right]:[\mathrm{CPTM}]$ molar feed ratio of $100: 1: 4: 8$ in $10 \mathrm{~mL}$ of distilled water at room temperature under the protection of $\mathrm{N}_{2}$ containing the silanized PU substrates. The resulting PU substrates using CPTM as a ligand and with surface-grafted DMCHPS polymers (P(DMCHPS)) were referred to as the PU-Si-g-P(DMCHPS) membranes. And these membranes with different reaction time were referred to as the PU-Si- $g$-P(DMCHPS)-12 h, PU-Si- $g$ P(DMCHPS)-24 h, PU-Si- $g$-P(DMCHPS)-36 h and PU-Si- $g$ $\mathrm{P}(\mathrm{DMCHPS})-48 \mathrm{~h}$ membranes, respectively. After the reaction, the PU-Si-g-P(DMCHPS) hybrid was washed thoroughly with the copious amount of distilled water to ensure the complete removal of the adhered and physically adsorbed polymers, if any.

\subsection{Characterization of both DMCHPS and polymers}

The static contact angle was performed on a dynamic/static contact angle instrument manufactured by Kino industrial Company Ltd at room temperature and standard atmospheric pressure. A Thermo-Nicolet Nexus-670 unit equipped with a DTGS detector (Thermo Instrument Co., Madison, WI) was used for all spectra acquisition. Samples were placed under a zinc selenide (ZnSe) attenuated total reflectance (ATR) crystal accessory and a torque of $-20 \mathrm{~N} \mathrm{~cm}$ was applied to ensure full contact. 200 co-added scans were collected at a resolution of $2 \mathrm{~cm}^{-1}$ within the region of $4000-600 \mathrm{~cm}^{-1} .{ }^{1} \mathrm{H}$ NMR was tested by $400 \mathrm{MHz}$ WB Solid-State NMR Spectrometer, Switzerland. Xray photoelectron spectroscopy was performed on a Versa Probe electron spectrometer instrument manufactured by ULVACPHI, Japan. The morphology of the pristine material, materials adhered to bacteria were observed on a JSM-5610 Scanning electron microscope instrument manufactured by JEOL company, Japan. The SEM samples were coated using gold sputtering.

\subsection{Inhibition kinetics of DMCHPS}

To added a certain amount of $S$. aureus and $E$. coli in different concentrations of DMCHPS $(2,1,0.5,0.25,0.125$ and $0 \mathrm{mg}$ $\mathrm{mL}^{-1}$ ), draw from each tube added to the 96-well plates, with BioTek Synergy 2 enzyme standard instrument the changes of the value of $\mathrm{OD}_{630}$ within $24 \mathrm{~h}$, and the data measured and recorded every 10 minutes at a time.

\subsection{Bacteria adhesion}

The samples were cut into square pieces and then immersed in PBS (pH 7.4, 0.8\% NaCl, 0.02\% KCl, 0.144\% $\mathrm{Na}_{2} \mathrm{HPO}_{4}$, and $0.0024 \% \mathrm{NaH}_{2} \mathrm{PO}_{4}$ ) for $2 \mathrm{~h}$ before they were dried and exposed to UV lamp for $30 \mathrm{~min}$.

\subsection{Bacterial strain}

Escherichia coli and Staphylococcus aureus were used for adhesion experiments. The bacteria were kept at $-80{ }^{\circ} \mathrm{C}$ in $\mathrm{PE}$ tube containing enough trypticase soy broth (TSB) and 10\% glycerol. Before the experiment, bacteria were released from the tube and grown in TSB at $37{ }^{\circ} \mathrm{C}$ under static conditions with shaking for $24 \mathrm{~h}$. After that, bacterial strain diluted 100-fold into fresh medium (TSB) were transferred to 24-well microtiter plate which contains samples already. Then the 24-well microtiter plate was kept at $37{ }^{\circ} \mathrm{C}$ under static conditions with shaking for $24 \mathrm{~h}$. The samples were washed with PBS more than 3 times, and the dead bacteria were fixed by glutaraldehyde solution $(2.5 \%, \mathrm{v} / \mathrm{v})$ afterward. Finally, samples were dehydrated by different ethanol $(25 \%, 50 \%, 70 \%, 80 \%$, 90\% and 100\%) solutions respectively.

\subsection{Protein adsorption (PA)}

The film by PBS soaked into 24-well plates, each well was added $2 \mathrm{~mL}$ of fetal bovine serum proteins. The sample was kept at $37^{\circ} \mathrm{C}$ for $60 \mathrm{~min}$, and then with a freshly prepared PBS rinsed 3 times to wash away the physical adsorption of proteins. Then the sample was placed in a PBS solution containing 1\% SDS in $1 \mathrm{~h}$ shaking to elute adsorbed proteins. BCA kit was used to test the protein in the elution solution and read the O.D. value under $562 \mathrm{~nm}$, then compared with the O.D. value of the standard curve, so as to calculate the total amount of adsorbed protein on the surface of the membrane.

\subsection{In vitro cytotoxicity assays (MTT)}

Different concentrations of DMCHPS, PU-Si-g-P(DMCHPS)$12 \mathrm{~h}, \mathrm{PU}-\mathrm{Si}-\mathrm{g}$-P(DMCHPS)-24 h, PU-Si-g-P(DMCHPS)-36 h and PU-Si- $g$-P(DMCHPS)-48 h were prepared in DMEM cell culture medium and kept at $\mathrm{CO}_{2}$ incubator for $24 \mathrm{~h}$. Be taken for logarithmic growth period of HEK293 cells, abandoned to the culture medium with $2 \mathrm{~mL}$ of PBS buffer washing two times, add $1 \mathrm{~mL}$ trypsin digestion, until a small white particles from cell culture bottle wall off abandoned to trypsin, added $3 \mathrm{~mL}$ DMEM culture medium containing $10 \%$ fetal calf serum to terminate the cell digestion, pipetting the cells about 50 times, making it the single cell suspension to $1 \times 10^{5}$ cell per well were seeded in 96-well plates, $100 \mu \mathrm{L}$ cell suspension was added to each well, kept at $\mathrm{CO}_{2}$ incubator for $24 \mathrm{~h}$, discard the original culture medium in 96-well plates, the Central Plains culture medium was added to the prepared solution, blank control group with $100 \mu \mathrm{L}$ DMEM culture fluid. After the 96 hole plate is put into the $\mathrm{CO}_{2}$ incubator and cultured for $24 \mathrm{~h}$, add $20 \mu \mathrm{L} \mathrm{MTT} \mathrm{solu-}$ tion for each hole to contact $4 \mathrm{~h}$, then $100 \mu \mathrm{L}$ DMSO was added to each well to dissolve the resulting formazan. The absorbance was measured at $562 \mathrm{~nm}$ using a BioTek Synergy 2 Multi-Mode 
Microplate Reader. The determination of cell relative increment rate from this formula:

$$
\mathrm{RGR}=\left[\left(D_{\mathrm{t}}-D_{\mathrm{b}}\right) /\left(D_{\mathrm{nc}}-D_{\mathrm{b}}\right)\right] \times 100 \%
$$

where $D_{\mathrm{t}}$ is the absorbance of the sample, $D_{\mathrm{nc}}$ is negative absorbance in the control group; $D_{\mathrm{b}}$ is the absorbance of the blank control group.

\subsection{HEK293 cells imaging on modified PU films}

Modified PU films were laid on the bottom of the 24-well plates, each well was added $2 \mathrm{~mL}$ of cell suspension solutions $\left(5 \times 10^{5}\right.$ cells per $\mathrm{mL})$. The plates were cultured in incubator $\left(37^{\circ} \mathrm{C}\right.$ in a humidified atmosphere containing $5 \% \mathrm{CO}_{2}$ ). After the predetermined time points $(24 \mathrm{~h}, 48 \mathrm{~h}$ ), samples were taken out, and the nonadherent cells were eliminated by PBS washing and the adherent cells were fixed with $2.5 \%$ glutaraldehyde for $4 \mathrm{~h}$. After that, cells were 4,6-diamidino-2-phenylindole dihydrochloride (DAPI) stained for nucleus $(50 \mu \mathrm{L}$ per sample, lucifuge for $10 \mathrm{~min}$ ). After that samples were visualized by fluorescent microscopy (Zeiss, Germany). ${ }^{\mathbf{4 3}}$

\section{Results and discussion}

\subsection{Reaction mechanism}

In our work, tertiary amine quaternization step synthesis method prepared zwitterionic monomer having sulfoammonium antibacterial properties (DMCHPS). The reaction function was seen in Fig. 1a. CPTM was acted as a coupling agent as well as a ligand in the process of RATRP. During the reaction process, $\mathrm{Cu}^{2+}$ first reacts with CPTM to form a kind of complex. This complex was then deprived of halide by free radicals generated in the process of RATRP. After that, a dormant halogenide and a metal complex with low valence were obtained. The color of the solution changed from blue to pale blue over time, and this proved the carrying out of the reaction on the other hand. $\mathrm{Cu}^{2+}$ and $\mathrm{Cu}^{+}$ coexisted in the reaction, and they achieved a dynamic balance. ${ }^{44}$ Finally, the solution has been pale blue. Fig. 1b shows the

a

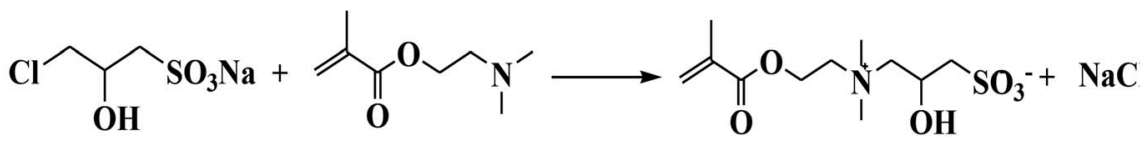

b
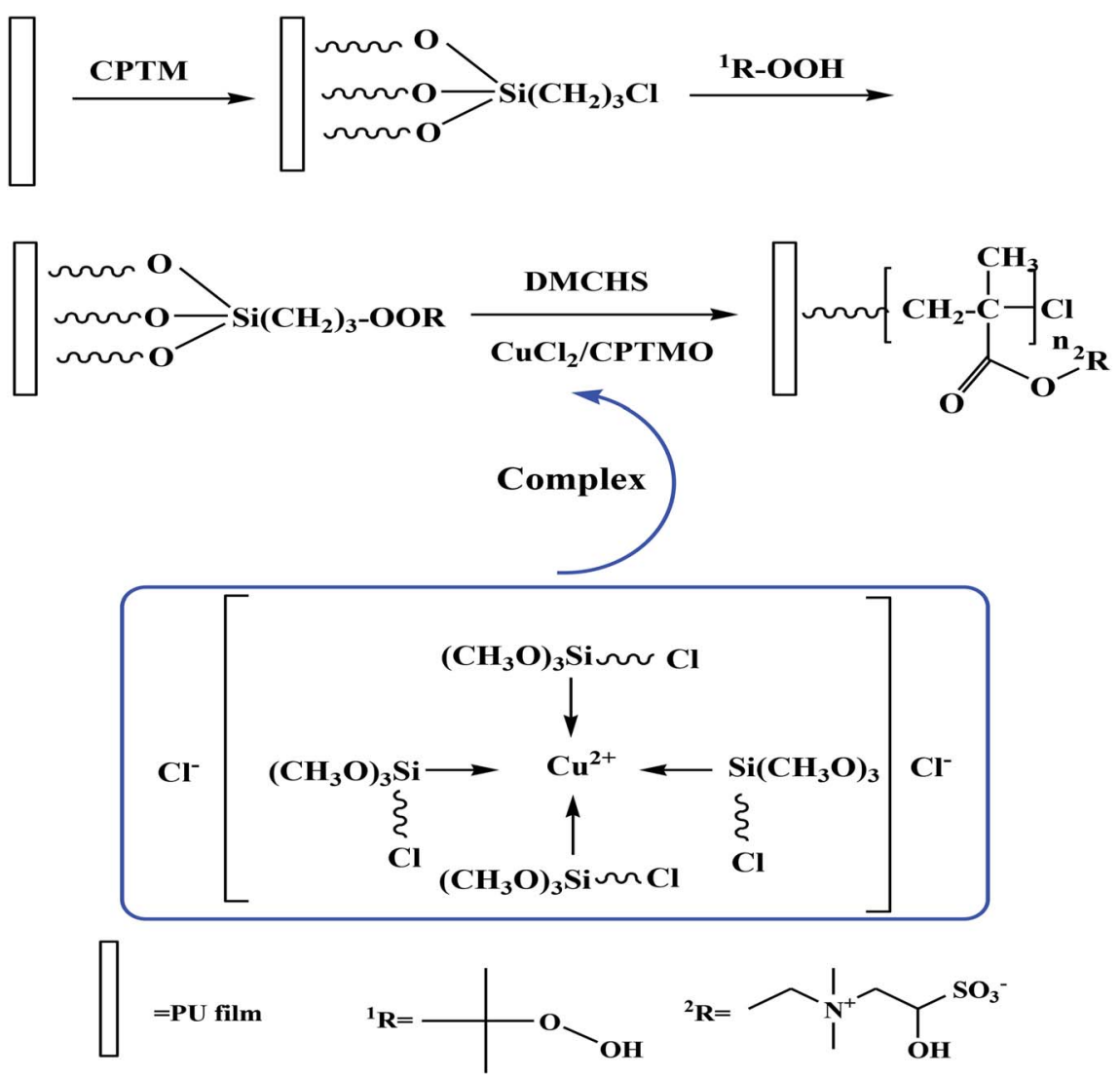

Fig. 1 (a) Reaction process of the preparation of DMCHPS. (b) Schematic diagram of the process of preparation of the PU-Si-g-P(DMCHPS) on the PU surface via RATRP method. 
reaction mechanism and process which was the basis for the following tests and characterizations.

\subsection{Hydrophilicity}

The hydrophilicity of DMCHPS and the PU-Si-g-P(DMCHPS) surface was evaluated by the contact angle measurement as described earlier. ${ }^{45}$ The DMCHPS has excellent hydrophilicity with its water contact angle much less than $90^{\circ}$ (Fig. 2d) while the PU-Si was hydrophobic with its water contact angle over $90^{\circ}$ (Fig. 2b). When the DMCHPS was grafted to the PU-Si surface the water contact angle was significantly decreased (Fig. 2c), indicating the hydrophilicity of the PU-Si surface was increased. Hydrophilic differences affect the biodegradability of the sample, and the better the hydrophilicity, the stronger the biodegradability. ${ }^{46-48}$ DMCHPS improves the hydrophilic properties of the polyurethane, so the biodegradability of modified polyurethane has been enhanced. As seen from Fig. 2a, the contact angle of PU substrates reduced gradually as the polymerization time prolonged and there was an approximately linear relationship between contact angle and reaction time, which demonstrated that process of the chain growth of DMCHPS on the surface of PU was a controllable "living" polymerization.

\subsection{Composition}

3.3.1 FTIR analysis. As illustrated in Fig. 3f, the $\mathrm{O}-\mathrm{H}$ stretching vibration was observed at $3360 \mathrm{~cm}^{-1}$; the $\mathrm{C}=\mathrm{O}$ stretching vibration was observed at $1720 \mathrm{~cm}^{-1}$, and the peak at
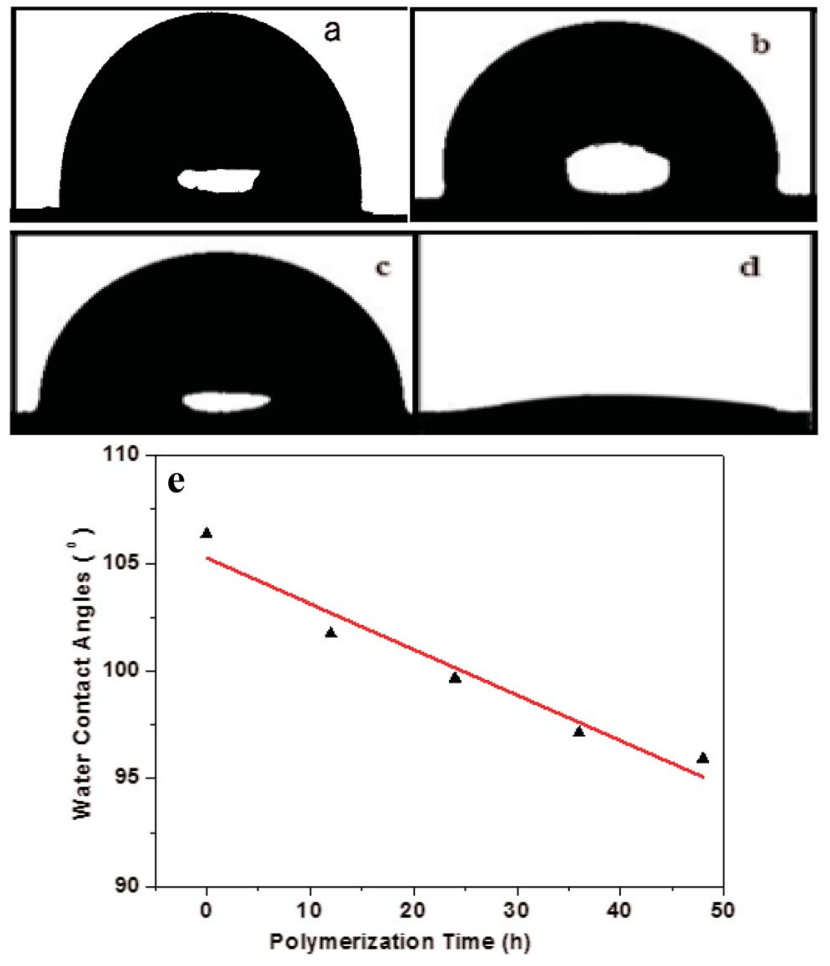

Fig. 2 (a) Water contact angle images of PU; (b) PU-Si; (c) PU-Si-gP(DMSCH)-48 h; (d) DMCHPS; (e) water contact angles of PU-Si, PUSi-g-P(DMSCH)-12 h, PU-Si-g-P(DMSCH)-24 h, PU-Si-g-P(DMSCH)$36 \mathrm{~h}, \mathrm{PU}-\mathrm{Si}-\mathrm{g}-\mathrm{P}(\mathrm{DMSCH})-48 \mathrm{~h}$.

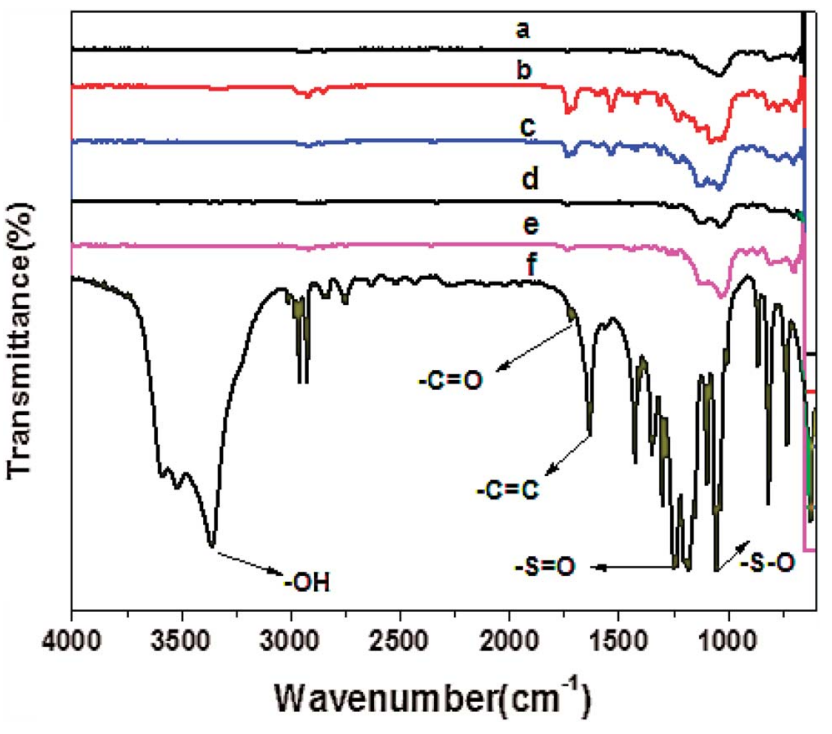

Fig. 3 (a) FTIR of PU-Si, (b) FTIR of PU-Si-g-P(DMSCH) $-12 \mathrm{~h}$, (c) FTIR of PU-Si-g-P(DMSCH)-24 h, (d) FTIR of PU-Si-g-P(DMSCH)-36 h, (e) FTIR of PU-Si-g-P(DMSCH) -48 h, (f) FTIR of DMCHPS.

$1630 \mathrm{~cm}^{-1}$ should come from the $\mathrm{C}=\mathrm{C}$ stretching vibration. The bands at $1245 \mathrm{~cm}^{-1}$ and $1040 \mathrm{~cm}^{-1}$ can be attributed to the $\mathrm{S}=\mathrm{O}$ and $\mathrm{S}-\mathrm{O}$ vibration. All these evidence proved that zwitterionic monomer (DMCHPS) had been successfully synthesized. The peaks of $\mathrm{C}=\mathrm{C}$ vibration in Fig. 3b-e FTIR spectrum had disappeared, which roughly indicated that the monomer was successfully grafted polymerized onto the PU-Si surface. From Fig. 3a, the intensity of $\mathrm{C}=\mathrm{O}$ peaks in $1720 \mathrm{~cm}^{-1}$ are obviously weaker than that in Fig. $3 \mathrm{~b}-\mathrm{e}$, which once again demonstrated that the monomer was grafted to the PU-Si surface since $\mathrm{PU}$ itself has the structure of $\mathrm{C}=\mathrm{O}$.

3.3.2 ${ }^{1} \mathbf{H}$ NMR spectra of DMCHPS. The structure and purity of DMCHPS were characterized using ${ }^{1} \mathrm{H}$ NMR analysis (Fig. S1 $\dagger$ ). The result showed chemical shifts of vinyl protons at $6.09 \mathrm{ppm}$ and $5.75 \mathrm{ppm}$. Methyl protons next to nitrogen at $3.48 \mathrm{ppm}$, methyl protons next to vinyl protons at $1.91 \mathrm{ppm}$, methylene protons next to the ester group at $4.52 \mathrm{ppm}$, methylene protons next to the sulfobetaine group were located at $3.71 \mathrm{ppm}$, methylene protons between sulfobetaine group and the hydroxyl groups were located at $2.50 \mathrm{ppm}$, the left methylene protons were located at $2.01 \mathrm{ppm}$. Methine protons were located at $3.06 \mathrm{ppm}$. (400 MHz, methanol-d4), $\delta 4.46(\mathrm{~d}, J=8.5 \mathrm{~Hz}, 2 \mathrm{H}), 4.18(\mathrm{~m}, 4 \mathrm{H})$, $1.94(\mathrm{~s}, 6 \mathrm{H}), \delta 1.34(\mathrm{t}, J=7.1 \mathrm{~Hz}, 6 \mathrm{H}) \mathrm{ppm}$.

3.3.3 XPS analysis. The XPS spectra and the model fits are shown in Fig. 4a-j for $\mathrm{N} \mathrm{1s,} \mathrm{S} \mathrm{2p,} \mathrm{C} \mathrm{1s,} \mathrm{and} \mathrm{O} \mathrm{1s} \mathrm{peaks,} \mathrm{respec-}$ tively. The optimized parameters such as the fit component peak positions, peak widths, and area percentages are summarized in Table $\mathrm{S} 1, \uparrow$ these spectra will be discussed sequentially below.

Table $\mathrm{S} 1 \uparrow$ lists the detailed data from XPS scan on different surfaces. As seen from Table $S 1, \uparrow$ the concentration of sulfur in PU substrates with different polymerization time was extremely low, which was a well-known limitation of the method of ATRP. Compared to the blank sample PU-Si, the concentration of $\mathrm{C} 1 \mathrm{~s}$, Si $2 p$ from DMCHPS was lower while the concentration of $\mathrm{O} 1 \mathrm{~s}$ 

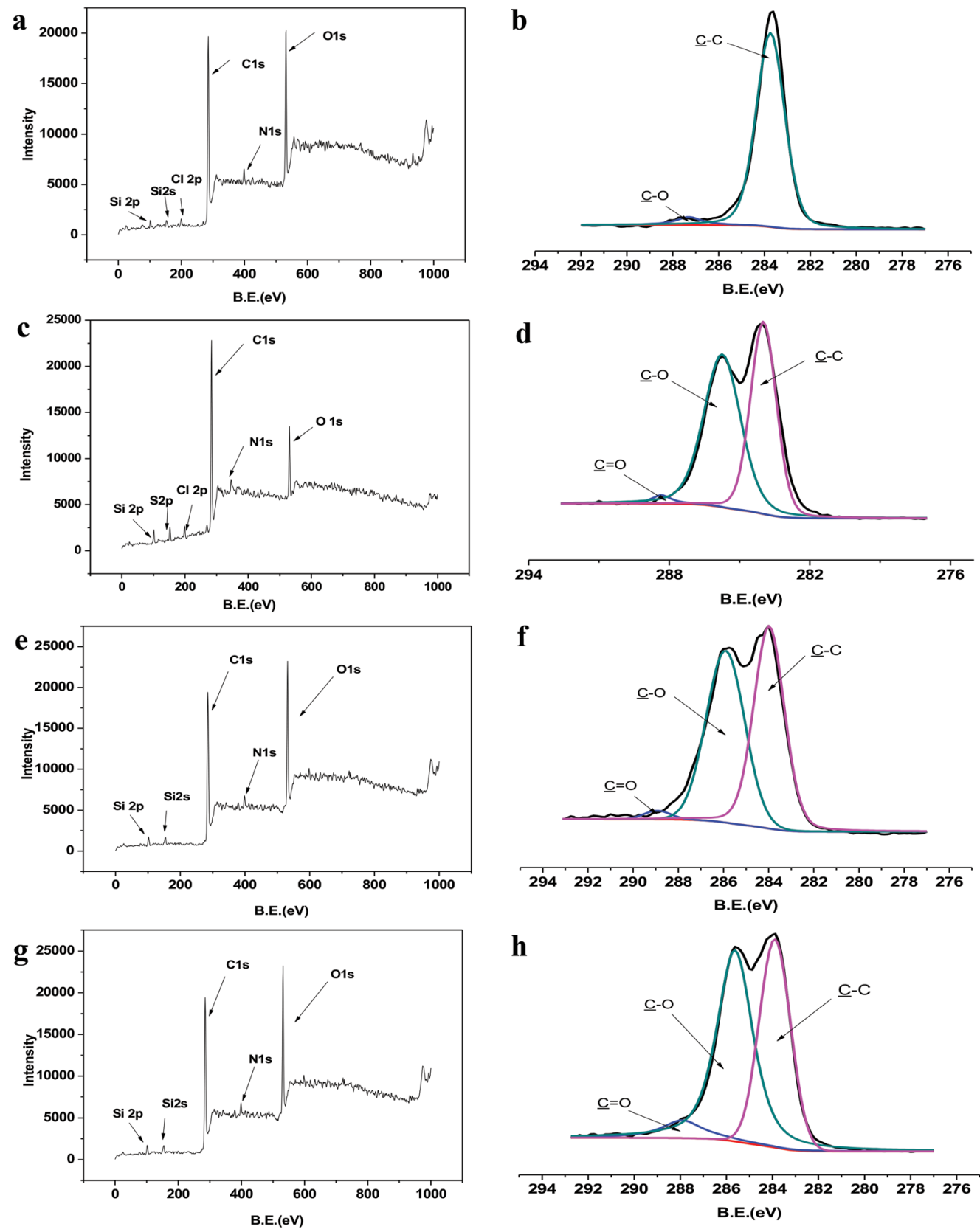

h
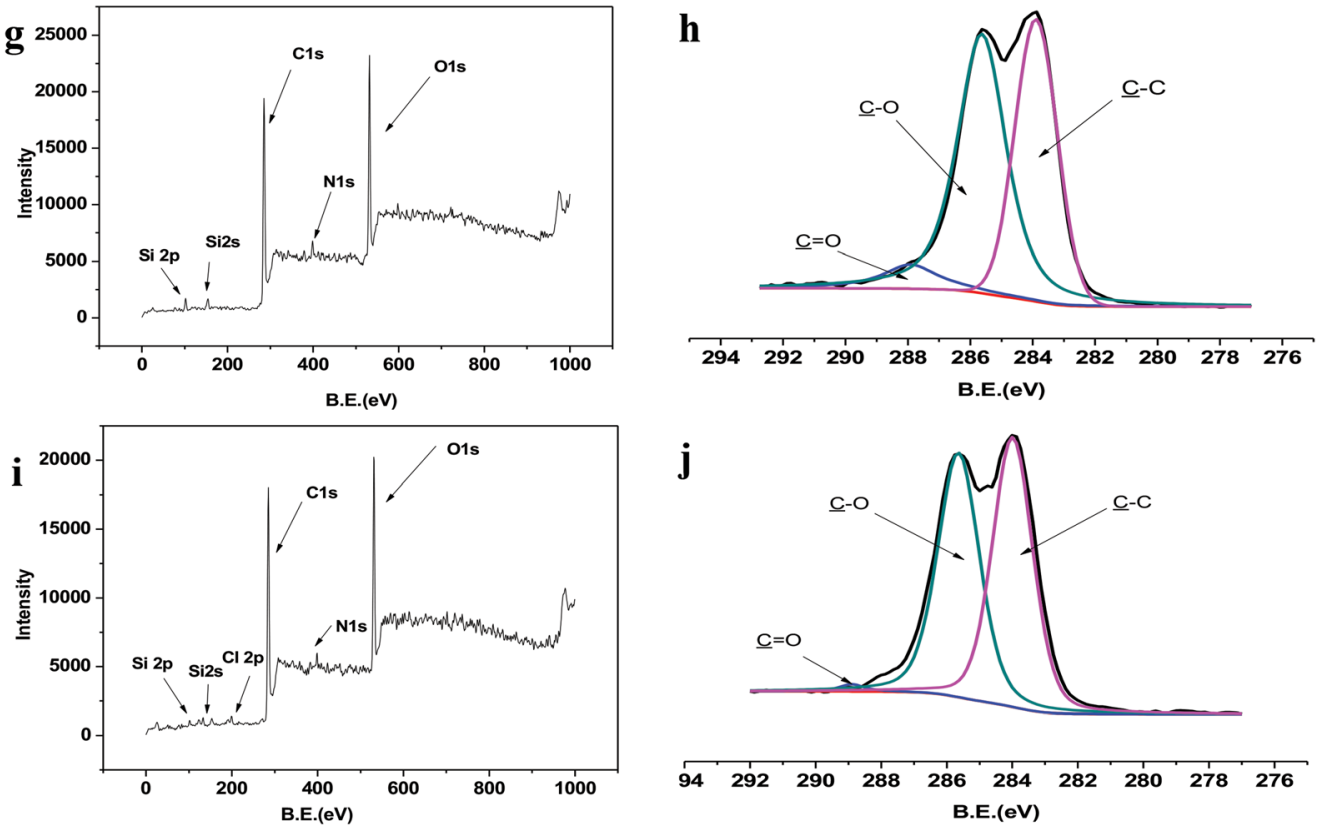

Fig. 4 (a) XPS survey spectra of PU-Si, (c) PU-Si-g-P(DMSCH)-12 h, (e) PU-Si-g-P(DMSCH)-24 h, (g) PU-Si-g-P(DMSCH)-36 h, (i) PU-Si-g$\mathrm{P}(\mathrm{DMSCH})-48 \mathrm{~h}$; (b) Magnified characteristic peaks of $\mathrm{C}-\mathrm{C}, \mathrm{C}-\mathrm{O}$ and $\mathrm{C}=\mathrm{O}$ of $\mathrm{PU}-\mathrm{Si}$, (d) PU-Si-g-P(DMSCH)-12 h, (f) PU-Si-g-P(DMSCH)-24 h, (h) PU-Si-g-P(DMSCH)-36 h, (j) PU-Si-g-P(DMSCH)-48 h. 
and $\mathrm{N}$ 1s was higher. Thus the content of $\mathrm{C}$ 1s, Si 2p from PU-Si$g$-P(DMSCH)-12 h was smaller than blank sample while $\mathrm{O} 1 \mathrm{~s}$ and $\mathrm{N}$ 1s larger. That was because after the reaction was conducted for $12 \mathrm{~h}$, some DMCHPS was grafted to the blank surface. In addition, as the interaction time going on, the element content of samples gets much greater if the content of PU-Si-g-P (DMSCH)-12 h sample was larger than the blank sample. At the same time, the element content of samples gets much smaller if the content of PU-Si- $g$-P (DMSCH)-12 h sample was smaller than the blank sample. That was because as the interaction time increased more and more DMCHPS was grafted to the surface of PU.

Table $\mathrm{S} 1 \dagger$ also lists the total atomic ratio of $\mathrm{O} / \mathrm{C}$ increased from 0.34 to 0.38 . This atomic ratio change once again demonstrated that more and more DMCHPS grafted to PU surface, as the atomic ratio of DMCHPS (0.63\%) was much larger than $\mathrm{PU}-\mathrm{Si}(0.16 \%)$. The total atomic ratio of $\mathrm{O} / \mathrm{C}$ also expresses the grafted layer of DMCHPS. The grafted layer showed an approximately linear growth over time (Fig. S2 $\dagger$ ), which demonstrated that process of the chain growth of DMCHPS on the surface of PU was a controllable one and was a "living" polymerization.

As seen from the narrow scan spectra of C 1s (Fig. 4b and d), the $\mathrm{C}$ 1s peaks in PU-Si and PU-Si- $g-\mathrm{P}(\mathrm{DMSCH})-12 \mathrm{~h}$ are mainly attributed to the over-lap of binding energy peaks of $\mathrm{C}-\mathrm{H}$ (containing C-C at $\sim 285.0 \mathrm{eV}), \mathrm{C}-\mathrm{O}(\sim 286.6 \mathrm{eV})$, and $-\mathrm{C}=\mathrm{O}(\sim 288.0$ $\mathrm{eV}$ ). $\mathrm{PU}$ has fewer $\mathrm{C}=\mathrm{O}$ species than $\mathrm{C}-\mathrm{O}$ species in its molecular chain, the peak at $288.0 \mathrm{eV}$ is smaller than that at $286.6 \mathrm{eV}$. However, there were no $\mathrm{C}=\mathrm{O}$ peaks on the PU-Si surface (Fig. 4b), indicating that DMCHPS was indeed immobilized on the surface. This is because CPTM not contain $\mathrm{C}=\mathrm{O}$ bond while DMCHPS does. Simultaneously, we can see from Fig. $4 \mathrm{~d}-\mathrm{j}$, with increasing reaction time, samples showing the peak at $288.0 \mathrm{eV}$ and $288.0 \mathrm{eV}$ at the relative area of the peaks increases, further confirmed DMCHPS immobilized on the polymer surface.

\subsection{Antimicrobial activity}

The antimicrobial activities of the compound (DMCHPS) and polymers were then tested against a range of pathogenic and non-pathogenic microorganisms, including Gram-negative bacteria (E. coli) and Gram-positive bacteria (S. aureus). ${ }^{49}$ As shown in Fig. 5a, the result of the assays indicated that DMCHPS exhibited strong antimicrobial activities against Gram-negative bacteria with MIC of $25 \mu \mathrm{M}$. Observed from Fig. 5b, however, DMCHPS concentration is greater than $0.125 \mathrm{mg} \mathrm{mL} \mathrm{m}^{-1}$, O.D. values gradually decrease, and when the solution concentration of $1 \mathrm{mg} \mathrm{mL}^{-1}$, O.D. minimum value has been basically can inhibit the growth of $S$. aureus. Therefore, DMCHPS of $S$. aureus minimum bacteriostatic concentration of $1.0 \mathrm{mg} \mathrm{mL}^{-1}$. The MIC value is comparable or better than many new systems developed recently. ${ }^{45,50}$

The time-dependent efficiencies of antimicrobial activities of the polymer against $S$. aureus and $E$. coli were then investigated by bacterial adhesion test. The shape and number of the microorganism on the surface of the samples were observed by scanning electron microscope ( $S$. aureus Fig. $6 \mathrm{a}-\mathrm{e}^{\prime}$, E. coli Fig. S3a- $\left.\mathrm{e}^{\prime} \dagger\right)$. From that Fig. $6 \mathrm{e}$ and $\mathrm{S} 3 \mathrm{e}, \dagger$ we can see the shape of both the $S$. aureus and $E$. coli were in good condition, that means the samples were not able to kill the bacteria. Bacteria on the PU-Si- $g$-P(DMCHPS)-12 h sample didn't change so much, the shape and size were nearly the same as the living bacteria (Fig. 6a and S3a $\dagger$ ). The margin of bacteria on the PU-Si-g$\mathrm{P}$ (DMCHPS)-24 h sample became vague that means the bacteria were affected to some extent (Fig. $6 \mathrm{~b}$ and $\mathrm{S} 3 \mathrm{~b} \dagger$ ). Bacteria are seen on pictures from Fig. $6 \mathrm{c}-\mathrm{d}$ and $\mathrm{S} 3 \mathrm{c}-\mathrm{d} \dagger$ were wizened or even totally broken, which demonstrated that both $S$. aureus and $E$. coli were killed by the polymers. These facts proved that, as the interaction time going on, the antimicrobial ability of the polymers increased. We hypothesize that the zwitterionic polymer brushes can strongly hydrate the surface, which can prevent biofouling behaviour on the interface. ${ }^{45,50-52}$

\subsection{Protein adsorption (PA)}

This study tested the sulfonated ammonium zwitterionic polymer coating on the adsorption of bovine serum albumin. Fig. 7 is a graph of different PU matrix protein adsorption. PU, PU-Si$g$-P(DMCHPS)-12 h, PU-Si-g-P(DMCHPS)-24 h, PU-Si-g$\mathrm{P}$ (DMCHPS)-36 h, and PU-Si- $g$-P(DMCHPS)-48 $\mathrm{h}$ membrane
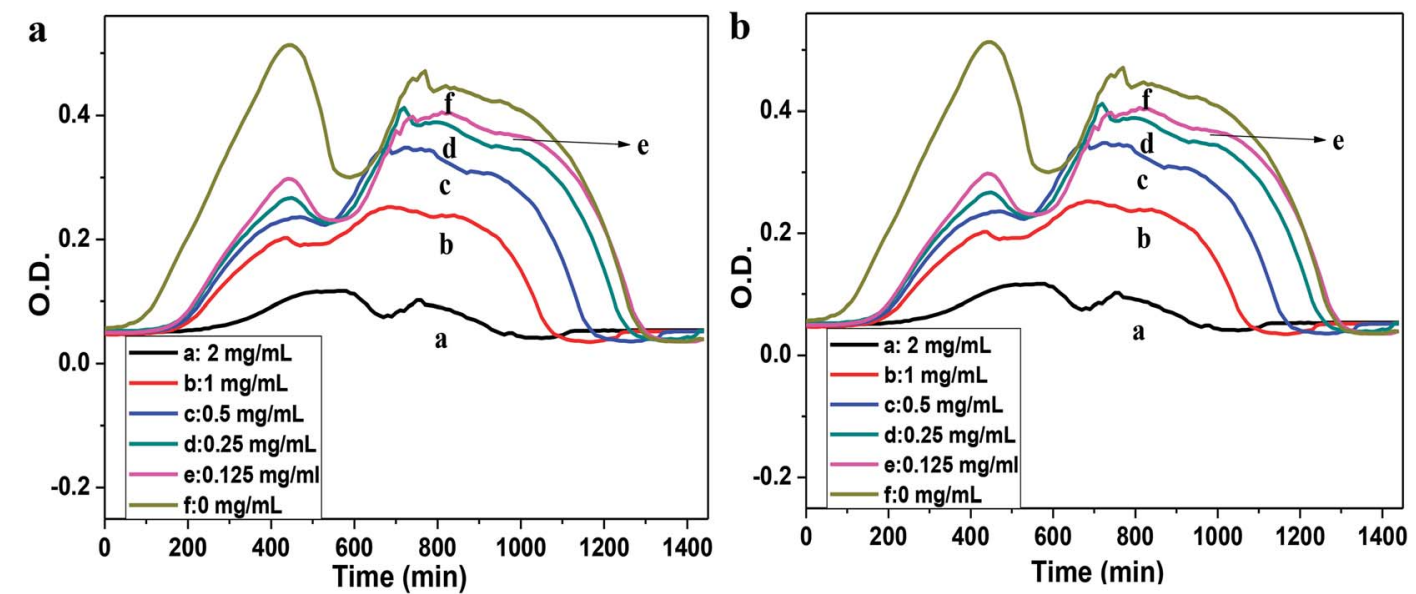

Fig. 5 (a) Inhibitory kinetic curves of different concentrations of DMCHPS with the same amount of E. coli. (b) Inhibitory kinetic curves of different concentrations of DMCHPS with the same amount of $S$. aureus. 


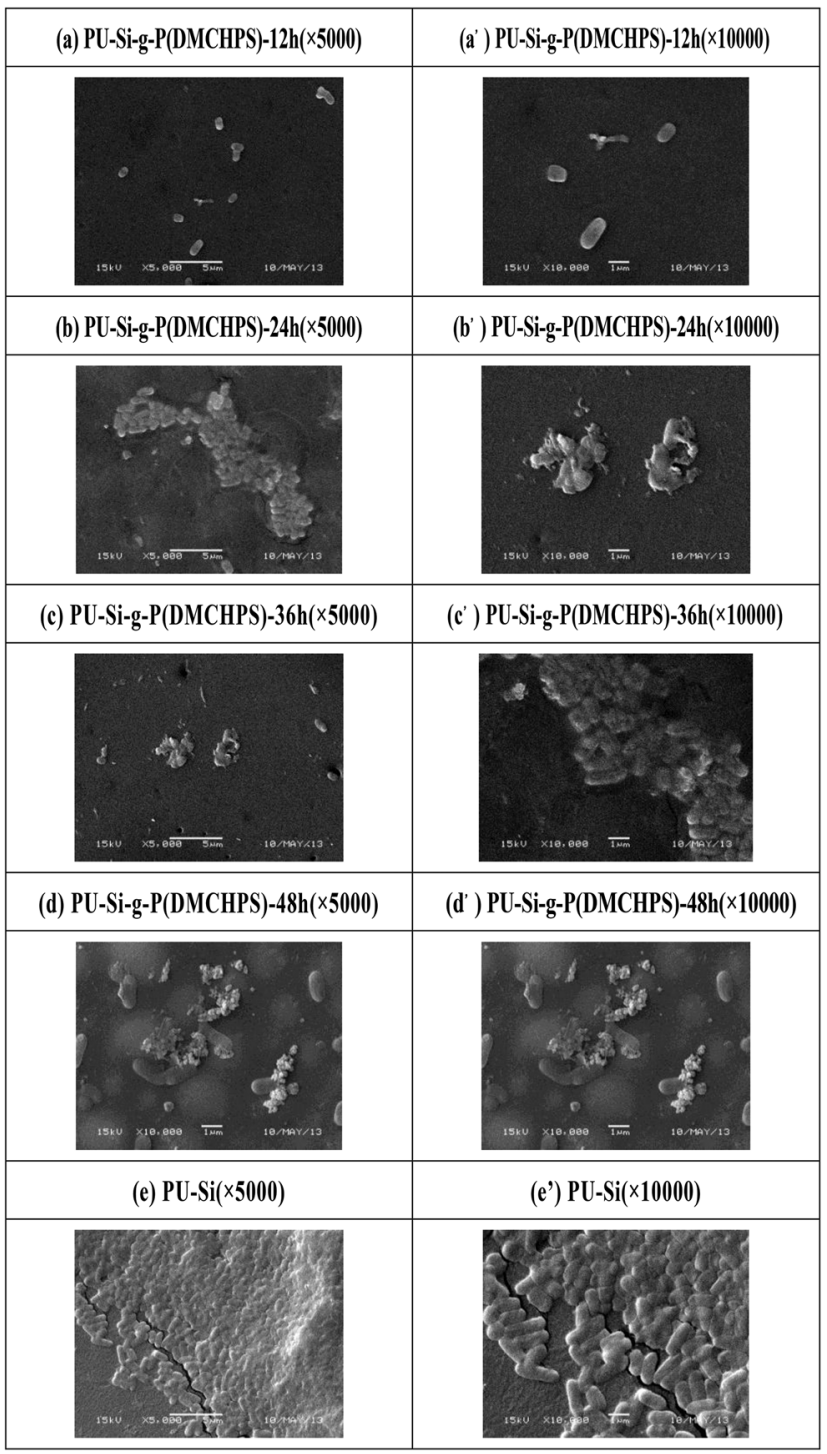

Fig. 6 SEM pictures of bacterial adhesion for (a and $a^{\prime}$ ) PU-Si-g$\mathrm{P}(\mathrm{DMSCH})-12 \mathrm{~h}$, (b and $\left.\mathrm{b}^{\prime}\right) \mathrm{PU}-\mathrm{Si}-\mathrm{g}-\mathrm{P}(\mathrm{DMSCH})-24 \mathrm{~h}$, (c and $\left.\mathrm{c}^{\prime}\right) \mathrm{PU}-\mathrm{Si}-$ $g$-P(DMSCH)-36 h, (d and d') PU-Si-g-P(DMSCH)-48 h, (e and e') PUSi against $S$. aureus. protein adsorption concentration were $16.496 \mu \mathrm{g} \mathrm{mL}{ }^{-1}, 14.624$ $\mu \mathrm{g} \mathrm{mL}{ }^{-1}, 14.232 \mu \mathrm{g} \mathrm{mL}{ }^{-1}, 13.125 \mu \mathrm{g} \mathrm{mL}^{-1}$ and $13.824 \mu \mathrm{g} \mathrm{mL}^{-1}$. Therefore, PU membrane protein adsorption quantity per unit area was $1.031 \mu \mathrm{g}\left(\mathrm{mL}^{-1} \mathrm{~mm}^{2}\right)$. However, PU-Si- $g$-P(DMCHPS)$12 \mathrm{~h}, \mathrm{PU}-\mathrm{Si}-\mathrm{g}$-P(DMCHPS)-24 h, PU-Si-g-P(DMCHPS)-36 h and PU-Si-g-P(DMCHPS)-48 protein adsorption quantity per unit area were $0.914 \mu \mathrm{g} \mathrm{mL}{ }^{-1}, 0.874 \mu \mathrm{gL}^{-1}, 0.806 \mu \mathrm{g} \mathrm{mL} \mathrm{m}^{-1}$ and $0.864 \mu \mathrm{g} \mathrm{mL}^{-1}$. Than PU blank decreased by $11.3 \%, 15.2 \%$, $22.2 \%$ and $16.2 \%$. By data shows PU blank membrane protein adsorption quantity higher than that of modified materials, and with the increase of reaction time, the amount of protein adsorption decreased. Jiang group using sulfoammonium amphoteric monomer grafted onto the gold surface, and through the protein adsorption experiments show that this kind of amphoteric ion polymer surface can impedance protein adsorption. ${ }^{53}$ Therefore, it can be considered that the modified polyurethane by the ammonium ion polymer has certain antifouling property.

\subsection{In vitro cytotoxicity assays}

Fig. 8a and b shows the viability of HEK293 cells cultured on the leaching solution of DMCHPS. After $24 \mathrm{~h}$ of culture, the higher percentage of cell viability was found in the leaching solution of DMCHPS at different concentration $\left(2,2 \times 10^{-1}, 2 \times 10^{-2}, 2 \times\right.$ $10^{-3}, 2 \times 10^{-4}, 2 \times 10^{-5}$ and $2 \times 10^{-6} \mathrm{mg} \mathrm{mL}^{-1}$ ), comparing to $48 \mathrm{~h}$ of culture. The viability of HEK 293 cells cultured on the leaching solution of DMCHPS is shown in Fig. 8a and b. After 24 and $48 \mathrm{~h}$ of culture (Fig. $8 \mathrm{c}$ and d), the higher percentage of cell viability was found in the leaching solution of DMCHPS at different concentration. In the culture periods of 24 and $48 \mathrm{~h}$, HEK293 cells showed a distinctly cell viability after incubation with different concentrations of the DMCHPS. ${ }^{47}$ Experimental result showed that the synthesized PU-Si-g-P(DMCHPS) on HEK293 cells have a role in promoting growth, therefore it can be used as a potential material for medical dressing material with the function of promoting wound healing.

\subsection{HEK293 cells imaging on modified PU films}

As analyzed by the cell morphology, proliferation, and metabolic activity after culture for $24,48 \mathrm{~h}$, the modified PU films
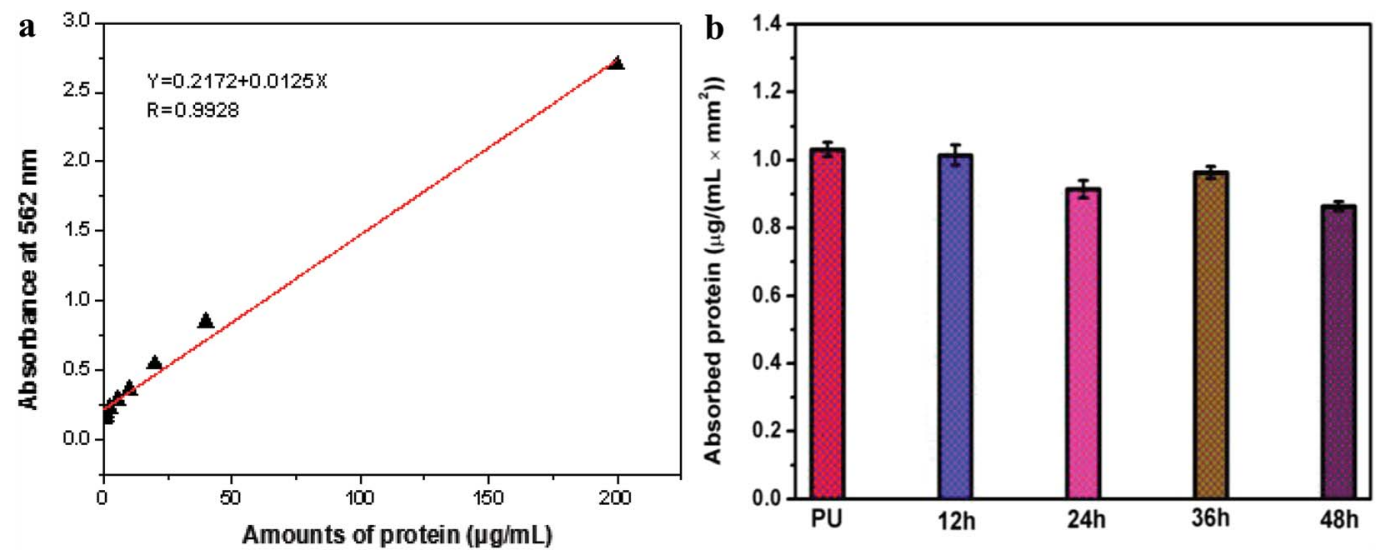

Fig. 7 (a) Standard curve for BSA concentration measurements. (b) Protein adsorption of PU-Si-g-P(DMCHPS) films with different reaction time. 

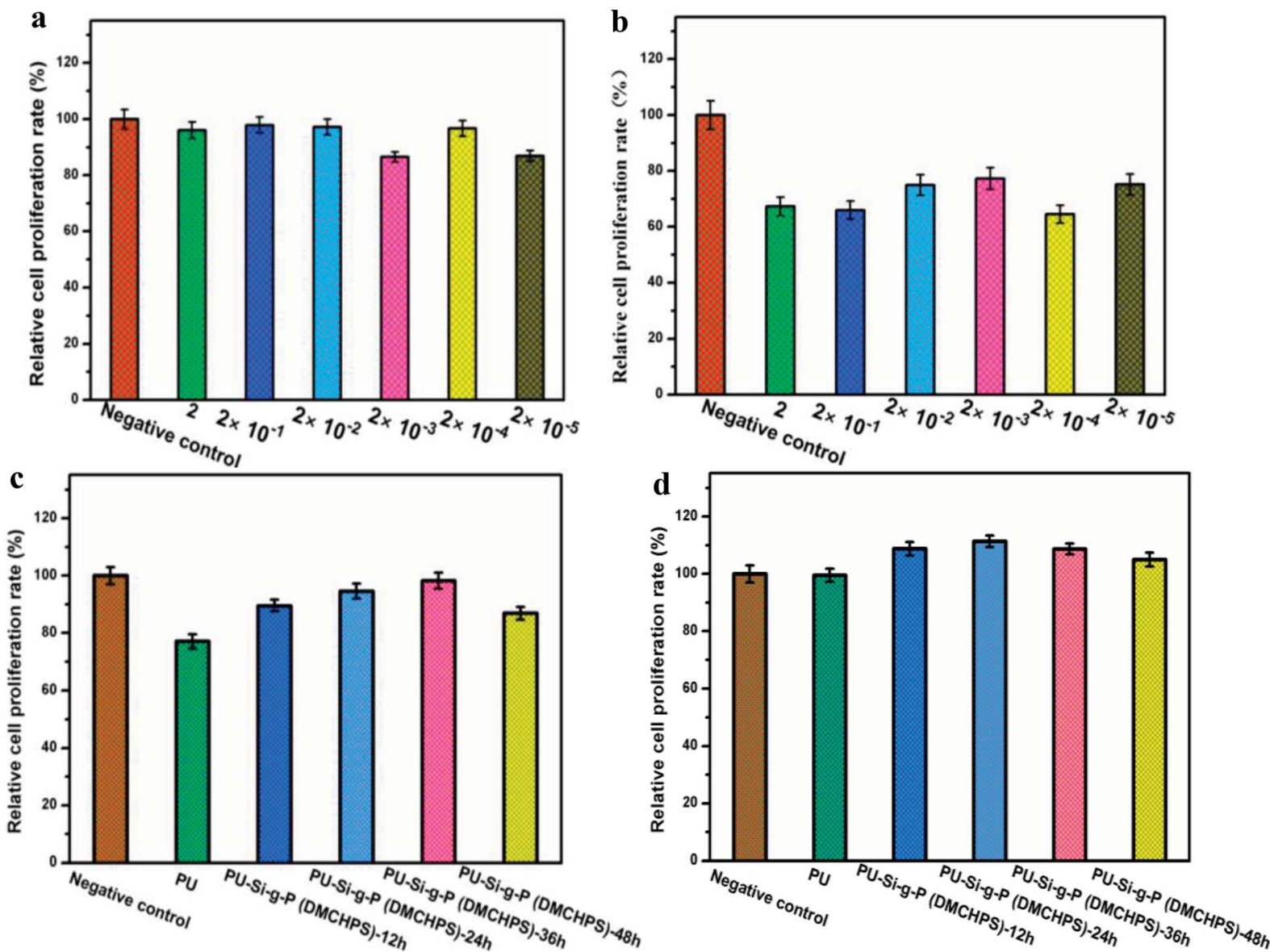

Fig. 8 Cell toxicity test results of DMCHPS $\left(2,2 \times 10^{-1}, 2 \times 10^{-2}, 2 \times 10^{-3}, 2 \times 10^{-4}, 2 \times 10^{-5}\right.$ and $\left.2 \times 10^{-6} \mathrm{mg} \mathrm{mL}^{-1}\right)$ with the wavelength at $490 \mathrm{~nm}$ during $24 \mathrm{~h} \mathrm{(a)}$ and $48 \mathrm{~h}$ (b). Cell toxicity test results of PU-Si-g-P(DMCHPS) with the wavelength at $490 \mathrm{~nm}$ during $24 \mathrm{~h}$ (c) and $48 \mathrm{~h}$ (d).

exhibited excellent biocompatibility. As shown in Fig. $\mathrm{S} 4, \dagger$ after being cultured for 24 and $48 \mathrm{~h}$, compared to the PU films, HEK293 cells were almost the same on the modified PU films. After being cultured for $24 \mathrm{~h}$, all the modified PU films presented significantly lower cell numbers, compared with $48 \mathrm{~h}$ of culture, indicating their good cellular biocompatibility.

\section{Conclusions}

In conclusion, we synthesized a compound with multiple-active functional groups which characterized itself in hydrophilicity and antimicrobial activity. Afterwards, the compound was grafted to the surface of PU via a new system of RATRP for different reaction time. Although the purity of this compound is not completely satisfactory, the following results of XPS and SCA confirmed that the PU films were successfully decorated by $\mathrm{P}$ (DMCHPS) and improved its hydrophilic property, thereby improving the biodegradability of the PU films. The improved antibacterial properties were verified by MIC and bacterial adhesion test. HEK293 cells showed a high percentage of viability when cultured in modified PU leaching solution. Therefore, antimicrobial activities of modified PU would be offering further potential in medical applications.

\section{Conflicts of interest}

There are no conflicts to declare.

\section{Acknowledgements}

This project was supported by the Jiangsu Six Category Outstanding Talent (2012-NY-031), Jiangsu Province Science and Technology support plan (BE2014327, BE2015367), the Jiangsu Agricultural Science and Technology Innovation Fund CX (15) 1016, JHB05-21 and Nanjing-321, the Priority Academic Program Development of Jiangsu Higher Education Institutions (PAPD). This project was also supported by the Jiangsu Collaborative Innovation Center of Biomedical Functional Materials.

\section{References}

1 Z. X. Zhang, X. Ni and J. Li, Polym. Int., 2014, 63, 1584-1592. 2 M. C. Wang, J. J. Lin, H. J. Tseng and S. H. Hsu, ACS Appl. Mater. Interfaces, 2012, 4, 338-350.

3 W. L. Chang, K. J. Peng, T. M. Hu, S. J. Chiu and Y. L. Liu, Polymer, 2015, 57, 70-76. 
4 A. F. Osman, G. A. Edwards, T. L. Schiller, Y. Andriani, K. S. Jack, I. C. Morrow, P. J. Halley and D. J. Martin, Macromolecules, 2012, 45, 198-210.

5 C. Chi, B. H. Sun, N. L. Zhou, M. Zhang, X. H. Chu, P. Yuan and J. Shen, Colloids Surf., B, 2018, 163, 301-308.

6 A. Koh, Y. Lu and M. H. Schoenfisch, Anal. Chem., 2013, 85, 10488-10494.

7 S. Q. Liu, B. P. Lin, X. D. Yang and Q. Q. Zhang, J. Phys. Chem. $B, 2007,111,1182-1188$.

8 P. B. Zetterlund, Y. Kagawa and M. Okubo, Chem. Rev., 2008, 108, 3747-3794.

9 M. H. Allen Jr, S. T. Hemp, A. E. Smith and T. E. Long, Macromolecules, 2012, 45, 3669-3676.

10 X. P. Chen, B. A. Sufi, A. B. Padias and H. K. Hall Jr, Macromolecules, 2002, 35, 4277-4281.

11 R. W. Simms and M. F. Cunningham, Macromolecules, 2008, 41, 5148-5155.

12 P. L. Ye, H. C. Dong, M. J. Zhong and K. Matyjaszewski, Macromolecules, 2011, 44, 2253-2260.

13 R. A. Sedjo, B. K. Mirous and W. J. Brittain, Macromolecules, 2000, 33, 1492-1493.

14 C. Liu, Y. Zhang and J. L. Huang, Macromolecules, 2008, 41, 325-331.

15 R. W. Simms and M. F. Cunningham, Macromolecules, 2007, 40, 860-866.

16 H. Q. Zhang and R. Van Der Linde, J. Polym. Sci., Part A: Polym. Chem., 2002, 40, 3549-3561.

17 I. Cakmak and H. Baykara, J. Appl. Polym. Sci., 2010, 102, 2725-2729.

18 L. L. Duan, Q. Q. Zhao, J. D. Liu and Y. T. Zhang, Environ. Sci.: Water Res. Technol., 2015, 1, 874-881.

19 X. D. Mao, H. Y. Sun, X. W. He, L. X. Chen and Y. K. Zhang, Anal. Methods, 2015, 7, 4708-4716.

20 A. Ronen, A. Resnick, S. Lerman, M. S. Eisen and C. G. Dosoretz, Desalination, 2016, 393, 159-165.

21 D. J. Haloi, B. P. Koiry, P. Mandal and N. K. Singha, J. Chem. Sci., 2013, 125, 791-797.

22 J. Wang, Y. P. Chen, K. Yao, P. A. Wilbon, W. Zhang, L. Ren, J. Zhou, M. Nagarkatti, C. Wang, F. Chu, X. He, A. W. Decho and C. Tang, Chem. Commun., 2012, 48, 916-918.

23 Y. J. Zheng, K. J. Yao, J. Lee, D. Chandler, J. F. Wang, C. P. Wang, F. X. Chu and C. B. Tang, Macromolecules, 2010, 43, 5922-5924.

24 B. Cao, L. Li, H. Wu, Q. Tang, B. Sun, H. Dong, J. Zhe and G. Cheng, Chem. Commun., 2014, 50, 3234-3237.

25 A. Vaterrodt, B. Thallinger, K. Daumann, D. Koch, G. M. Guebitz and M. Ulbricht, Langmuir, 2016, 32, 13471359.

26 Z. Zhang, T. Chao, S. F. Chen and S. Y. Jiang, Langmuir, 2006, 22, 10072-10077.

27 B. H. Sun, M. Zhang, N. L. Zhou, X. H. Chu, P. Yuan, C. Chi, F. Wu and J. Shen, RSC Adv., 2018, 8, 21369-21377.
28 S. A. Weicker, J. W. Dube and P. J. Ragogna, Organometallics, 2013, 32, 6681-6689.

29 Y. Terayama, M. Kikuchi, M. Kobayashi and A. Takahara, Macromolecules, 2011, 44, 104-111.

30 J. Cao, S. Zhai, C. Li, B. He, Y. Lai, Y. Chen, X. Luo and Z. Gu, J. Biomed. Nanotechnol., 2013, 9, 1847-1861.

31 J. M. Wang, H. Sun, J. J. Li, D. Y. Dong, Y. B. Zhang and F. L. Yao, Carbohydr. Polym., 2015, 117, 384-391.

32 L. Carr, G. Cheng, H. Xue and S. Jiang, Langmuir, 2010, 26, 14793-14798.

33 P. Mary and D. D. Bendejacq, J. Phys. Chem. B, 2008, 112, 2299-2310.

34 W. H. Kuo, M. J. Wang, H. W. Chien, T. C. Wei, C. Lee and W. B. Tsai, Biomacromolecules, 2011, 12, 4348-4356.

35 M. Tanaka, K. Sato, E. Kitakami, S. Kobayashi, T. Hoshiba and K. Fukushima, Polym. J., 2014, 47, 114-121.

36 M. Khan, J. Yang, C. Shi, Y. Feng, W. Zhang, K. Gibney and G. N. Tew, Macromol. Mater. Eng., 2015, 300, 802-809.

37 S. U. Na and C. A. O. Zhengmin, Appl. Mech. Mater., 2014, 731, 569-572.

38 F. Ai, Y. L. Yuan, Y. D. Wu, J. Zhou, J. Shen and S. C. Lin, Acta Polym. Sin., 2002, 4, 535-539.

39 J. Yuan, Y. L. Yuan, J. Shen and S. C. Lin, Chem. Res. Chin. Univ., 2003, 24, 916-919.

40 L. Z. Kong, C. G. Wang and G. Q. Zhai, Polym. Mater. Sci. Eng., 2011, 27, 65-68.

41 Y. K. Yang, K. J. Yook and J. Tae, J. Am. Chem. Soc., 2005, 127, 16760-16761.

42 T. Ye, Y. H. Song and Q. Zheng, Colloid Polym. Sci., 2016, 294, 389-397.

43 X. Y. Zhang, J. Ge, B. Lei, Y. M. Xue and Y. P. Du, CrystEngComm, 2015, 17, 4064-4069.

44 C. Y. Lu, N. L. Zhou, D. Xu, Y. D. Tang, S. X. Jin, Y. Wu and J. Shen, Appl. Surf. Sci., 2011, 258, 618-626.

45 G. F. Du, Q. L. Cai, L. Zhao, H. X. Wei, J. Wang, X. Y. Wang, G. S. Guo and Q. S. Pu, Chem. Eng. J., 2012, 195, 132-139.

46 Y. Z. Du, J. Ge, Y. P. Shao, P. X. Ma, X. F. Chen and B. Lei, J. Mater. Chem. B, 2015, 3, 2986-3000.

47 Y. Z. Du, M. Yu, J. Ge, P. X. Ma, X. F. Chen and B. Lei, Adv. Funct. Mater., 2015, 25, 5016-5029.

48 Y. Z. Du, Y. M. Xue, P. X. Ma, X. F. Chen and B. Lei, Adv. Healthcare Mater., 2016, 5, 382-392.

49 M. Zhang, W. T. Wang, P. Yuan, C. Chi, J. Zhang and N. L. Zhou, Chem. Eng. J., 2017, 330, 1137-1147.

50 R. S. Chouhan, A. Qureshi and J. H. Niazi, J. Mater. Chem. B, 2014, 2, 3618-3625.

51 H. Pingle, P. Y. Wang, S. McArtuer and P. Kingshott, Antibacterial Surfaces, Springer, 2015, pp. 61-88.

52 A. White and S. Y. Jiang, J. Phys. Chem. B, 2011, 115, 660-667.

53 J. C. Hower, M. T. Bernards, S. Chen, H. K. Tsao, Y. J. Sheng and S. Jiang, J. Phys. Chem. B, 2009, 113, 197-201. 